\title{
Empirical Study of Patent Protection Rights on Corporate Revenues of International Seed Companies
}

\author{
Yao $\operatorname{Tan}^{1 *}$ \\ ${ }^{1}$ School of Economics and Management, Hubei Polytechnic University, China, 435003 \\ Corresponding Author: 208094@hbpu.edu.cn
}

\begin{abstract}
Rights of patent protection in seed industry are the most important components of intellectual property for agricultural companies, but they have not received much attention so far. Agricultural products have unique characteristics that differ from those of common patented products, therefore the corresponding patent protection rights also have characteristics that differ from common ones and may contribute differently to corporate revenues. This paper selects 15 years of relevant data from three international leading seed companies to form a panel, and empirically demonstrates the corporate revenue contribution of patent protection rights in the seed industry by two major panel analyzing methods, i.e. panel correction standard errors and feasibility generalized least squares. It is found that (1) seed industry patent protection rights can effectively and steadily enhance corporate revenue, but the effect is significantly lower than that of corporate assets and market condition; (2) individual differences in the utilization of seed industry patent protection rights among different companies are not significant, but the contribution of seed industry patent protection rights varies significantly under different years.
\end{abstract}

Keywords: Seed, Patent, Corporate, Revenue

\section{INTRODUCTION}

The patent protection right in seed industry mainly refers to the right to protect new plant varieties. Unlike traditional industrial patents, the patent protection rights have many unique characteristics in seed industry. Since the seed industry is one of major parts in agriculture, the patent protection rights of the seed industry share much in common with those of agricultural patents, such as strong externalities[1], prominent geographical, and biological characteristics [2, 3].

Previous researches on corporate patent protection rights generally focuses on industrial patents with clear product boundaries and a high degree of product standardization. Therefore, the industrial fields in these researches are relatively limited to industrial manufacturing [4], including equipment manufacturing [5] and pharmaceutical manufacturing [6-8]. Seed industries as well as others in agriculture are less considered.

So far, studies in agricultural patents primarily explore the exploit of the patents' externalities, the spillover effects of patents in relevant fields, e.g. poverty reduction [9], environmental improvement, and promoting regional economic growth [10], but less on the effects of patent protection rights for corporate revenues.

As one of important parts for highly innovative productions, protection rights in the seed industry, due to the high externality, once implemented will have a profound impact on the development of the local agricultural industry, therefore, some regions do not adopt strict protection measures for those rights in the seed industry from the overall social benefits [1]. Consequently, the protection for those rights is limited [11]. Given the different conditions in protection rights for seed industry, it remains to be answered whether the patent protection rights in seed industry may have the same effect as common patents in promoting corporate development and enhancing corporate competitiveness [12].

In the purpose to display the effect of patent protection rights on seed industry companies, this paper collects data from three representative international company to empirically testify the contribution of corporate revenues. 


\section{DATA AND MODEL SETTING}

\subsection{Companies and data sources}

For highlighting the representativeness of the research, data from a total of three representative international seed companies, Monsanto, Syngenta and Dupont Pioneer, were selected from 2003 to 2017 to form a panel for analysis. Among them, the company revenue data were mainly obtained from the annual reports of listed companies, and the number of patent protection rights were given by the statistical reports of the International Plant Variety Protection Organization (UPOV).

\subsection{Research Setting}

With reference to previous research results on the impact of patents on corporate performance, the following research model was selected.

Table 1 Variables

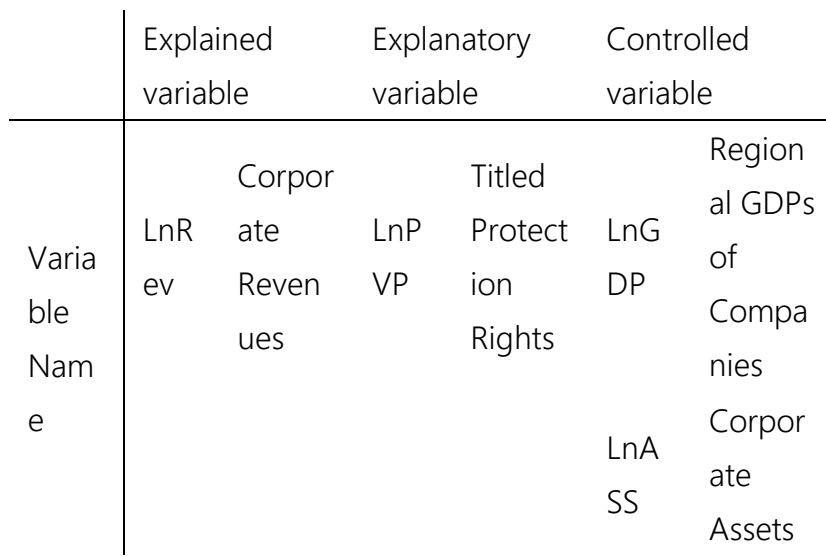

The basic linear model is based on the given data.

$\operatorname{Ln}(\operatorname{Re} v)=\alpha+\beta_{1} \operatorname{Ln}(P V P)+\beta_{2} \operatorname{Ln}(G D P)+\beta_{3} \operatorname{Ln}($ Ass $)+\varepsilon$

where $a$ is a constant term, $\beta$ is the coefficient to be estimated, and $\varepsilon$ is a random disturbance term.

\subsection{Estimation method}

For the validity of the empirical results, both Panel Corrected Standard Errors (PCSE) and Feasible
Generalized Least Squares (FGS) are adopted to estimate the panel data to obtain the most robust and efficient estimation results.

Since the target firms are at different stages of development and have different corporate strategies., the data are assumed to be heteroskedastic and autocorrelated .

\section{EMPIRICAL RESULTS}

\subsection{Data statistics}

Table 2 Statistics of Variables

\begin{tabular}{l|lllll} 
Variable & Obs & Mean & $\begin{array}{l}\text { Std. } \\
\text { Dev. }\end{array}$ & Min & Max \\
\hline LnRev & 45 & 9.4 & 0.6 & 8.4 & 10.5 \\
LnPVP & 45 & 5.0 & 0.7 & 3.8 & 6.3 \\
LnAss & 45 & 9.9 & 0.7 & 9.0 & 12.2 \\
LnGDP & 45 & 10.9 & 0.3 & 10.4 & 11.4
\end{tabular}

The above table reflects the basic statistics of the studied indicators.

\subsection{Methodological test}

In order to reflect the validity of the estimation results, unit root tests are conducted on the above data indicators.

Table 3 Unitroot Tests for Different Variables

\begin{tabular}{lrllll} 
& \multicolumn{2}{c}{ LLC } & \multicolumn{2}{c}{ IPS } \\
Variable & T Value & P Value & T Value & P Value \\
\hline LnRev & -2.6280 & 0.0043 & -1.7438 & 0.0406 \\
LnPVP & -2.4538 & 0.0071 & -1.8344 & 0.0333 \\
LnAss & -2.3545 & 0.0093 & -1.4039 & 0.0802 \\
LnGDP & -3.5686 & 0.0002 & -2.3121 & 0.0104
\end{tabular}

From the test results, we can see that the data of the selected research indicators are relatively smooth and suitable for effective regression analysis.

\subsection{Analytical results}

Table 4 Results of Estimations

\begin{tabular}{lllccccccc} 
Estimation & FE & PCSE & Two-way & Time & AR & & \multicolumn{3}{c}{ Two-way Time Fixed Het + AR } \\
& & & PCSE & fixed & PCSE & FGLS & FGLS & FGLS & FGLS \\
Variable Inrev & Inrev & Inrev & Inrev & Inrev & Inrev & Inrev & Inrev & Inrev \\
\hline
\end{tabular}




\begin{tabular}{|c|c|c|c|c|c|c|c|c|c|}
\hline & (0.169) & $(0.0525)$ & (0.160) & (0.0525) & $(0.0848)$ & (0.0379) & $(0.141)$ & $(0.0357)$ & $(0.0737)$ \\
\hline \multirow[t]{2}{*}{ Ingdp } & -0.0542 & -0.0262 & $0.352^{*}$ & $0.448 * \star \star$ & $0.583^{* \star \star}$ & -0.0262 & 0.352 & $0.448^{\star \star}$ & $0.630 * * \star$ \\
\hline & $(0.297)$ & (0.0844) & $(0.210)$ & $(0.148)$ & $(0.148)$ & $(0.0865)$ & $(0.241)$ & $(0.217)$ & (0.163) \\
\hline \multirow[t]{2}{*}{ Inpvp } & 0.00490 & $0.0476^{* * *}$ & 0.0446 & $0.0611^{\star * *}$ & $0.0497^{* *}$ & $0.0476^{*}$ & 0.0446 & $0.0611^{* \star}$ & $0.0576^{\star * * *}$ \\
\hline & (0.0689) & $(0.0160)$ & $(0.0399)$ & $(0.0159)$ & $(0.0224)$ & $(0.0257)$ & $(0.0457)$ & $(0.0248)$ & $(0.0187)$ \\
\hline \multirow[t]{2}{*}{ 2.company } & & & -0.0891 & & & & -0.0891 & & \\
\hline & & & $(0.160)$ & & & & (0.139) & & \\
\hline \multirow[t]{2}{*}{ 3.company } & & & 0.0318 & & & & 0.0318 & & \\
\hline & & & $(0.0566)$ & & & & (0.0714) & & \\
\hline \multirow[t]{2}{*}{ t } & & & $\begin{array}{c}- \\
0.0280^{* * *}\end{array}$ & $\begin{array}{c}- \\
0.0289^{* * *}\end{array}$ & $-0.0247^{\star \star \star}$ & & $-0.0280^{* *}$ & $-0.0289 * *$ & $-0.0215^{* *}$ \\
\hline & & & $(0.0106)$ & $(0.00813)$ & $(0.00830)$ & & (0.0129) & $(0.0122)$ & (0.00919) \\
\hline \multirow[t]{2}{*}{ Constant } & -1.119 & -0.989 & $-6.019 * * *$ & $-6.161^{* * *}$ & $-7.216^{\text {*** }}$ & -0.989 & $-6.019 * *$ & $-6.161^{\star \star \star}$ & $-7.392^{\star \star \star}$ \\
\hline & (2.330) & $(0.708)$ & (1.907) & $(1.541)$ & $(1.551)$ & $(0.833)$ & (2.394) & (2.326) & (1.699) \\
\hline Obs & 45 & 45 & 45 & 45 & 45 & 45 & 45 & 45 & 45 \\
\hline $\mathrm{R}^{2}$ & 0.850 & 0.959 & 0.964 & 0.964 & 0.998 & & & & \\
\hline \multicolumn{10}{|l|}{ Number } \\
\hline $\begin{array}{l}\text { of } \\
\text { company }\end{array}$ & 3 & 3 & 3 & 3 & 3 & 3 & 3 & 3 & 3 \\
\hline
\end{tabular}

\subsubsection{Differences in fixed effects}

Through the comparison of multiple estimation methods, the time fixed effect is more prominent, and the estimations of the time variable $t$ are relatively significant in all estimation methods involving time fixed effect. The signs of estimated values are the same, and values are approximate.

The results also reveal that the individual effects in the two-way fixed estimation methods are not prominent. The parameter estimated from the individual dummy variables are relatively consistent with the same signs, but none of the estimation results are statistically significant.

The coefficients estimated for dummy individual variables are not significant, which display the small variation among industrial leaders to obtain revenues from seed patents in the global market. The insignificant coefficients for dummy individual variables also may suggest that the capacities of different companies to utilize the new seed patents for revenues are approximate.

In contrast, the above estimation methods provide the significant results of time variable $\mathrm{T}$, inferring that companies in seed industry shares a lot of restrictions or incentives in common that are confined to the global development during different time intervals.

\subsubsection{Contribution of new seed protection rights to corporate revenue}

The results of different estimation methods are roughly convergent. The estimated values and signs of most coefficients are relatively similar. Except the fixed effects(FE) panel regression, the contributions of new seed varieties to revenue are roughly about 0.05 in most estimation methods, and the standard errors are about 0.02 , most of which are significant. By comparing the results of different estimation methods, it can be found that coefficients are relatively more significant from methods considering the autocorrelation and heteroskedasticity in data. The results of the FGLS estimation are more significant with smaller standard errors compared to those of the PCSE estimation, conforming to the general assumption that FGLS has relatively higher efficiency in contrast to the high robustness with PCSE. 


\section{DISCUSSION OF THE RESULTS}

\subsection{Differences in the contributions of assets, economic environment and new seed protection rights to corporate revenues}

From the results, it may unveil that corporate assets are the most important contributor to their revenues, as the coefficients for corporate assets from all estimations are significant and robust with the values all around about 0.1 , which is about 20 times of the coefficients of new seed protection rights.

Preceded by assets is regional GDP in the areas where the selected companies run their business, for which results of different estimations vary. Those from two way or time fixed estimations lay out better significant and robust than the rest, in which values are roughly about 0.3 to 0.6 with a relatively high standard errors compared to the results for assets. In terms of impacting corporate revenues, GDPs could still be generally considered a positive factor with the value of estimated coefficients 10 times as the new seed protection rights, despite of its lack of robustness.

Combining the above findings, it is inferred that corporate assets and new seed protection rights are effectively contributed to corporate revenues in terms of significance and robustness, and regional GDP may work progressively for revenues with a bigger uncertainty.

\subsection{Conclusion}

Countering the current recession of global economic, some agricultural companies tend to cut expenses and R\&D to survive. Through the review of 15 -year development history of three international leading seed companies, results may more suggest that one better way to fight against economic recession is relying on company itself with continuous $R \& D$ investment. Those measures proved effectively to bring in continuous and stable returns to revenues.

\section{ACKNOWLEDGMENT}

This work was supported by University Project of Hubei Polytechnic University(20xjz15R).

\section{REFERENCES}

[1].Luo, Z., C. Zou and Y. Wang, Analysis of the Plant Variety Protection Model under TRIPS:Different Solutions in Developed and Developing Countries. Scientific Management Research, 2006(01): p. 9295.
[2].Li, L. and Z. Li, Agricultural IP performance: logical starting point, focus and direction. Management World, 2014(10): p. 178-179.

[3].Li, X., The Study on Valuation of Agriculture Intellectual Propert. 2012, Hebei Agricultural University. p. 178.

[4].Mansfield, E., Patents and innovation: an emirical study. MANAGEMENT SCIENCE, 1986. 32(2): p. 173-181.

[5].Wang, M. and K. Chen, Research on the Relationship between Patents and Corporate Performance. Times Finance, 2011(4): p. 26-28.

[6].Zhu, G., J. Li and Y. Liu, Study on the Time-lag Effect of Different Patents Output on the Performance of Pharmaceutical Enterprises. Science and Management, 2019. 39(01): p. 44-50.

[7].Hou, Y. and X. Luo, Patent and performance of listed pharmaceutical companies. Central South Pharmacy, 2015. 13(09): p. 993-998.

[8].Zhou, X., L. Cheng and H. Wang, Is the higher the level of technological innovation the better the financial performance of enterprises? : An empirical study based on 16 years of patent application data of listed Chinese pharmaceutical companies. Journal of Financial Research, 2012(08): p. 166-179.

[9].Graff, G., D. Roland-Holst and D. Zilberman, Agricultural biotechnology and poverty reduction in low-income countries. World Development, 2006. 34(8): p. 1430-1445.

[10].Han, H., et al., Agricultural eco-efficiency loss under technology heterogeneity given regional differences in China. Journal of Cleaner Production, 2020. 250: p. 119511.

[11].Wang, X., Protection of New Varieties of Plants Model. Theory Research, 2014(05): p. 109-110.

[12].Lu, B., Research on the Seed Companies Continuing Operations in the Context of Plant Variety Protection in China. 2014, Northwest A\&F University. p. 107. 